\section{Developmental immunolocal- ization of the Klotho protein in mouse kidney epithelial cells}

\author{
J.H. Song, ${ }^{1}$ M.Y. Lee, ${ }^{2}$ Y.J. Kim, ${ }^{1}$ \\ S.R. Park, ${ }^{1}$ J. Kim, ${ }^{3}$ S.Y. Ryu, ${ }^{1}$ J.Y. Jung' \\ ${ }^{1}$ College of Veterinary Medicine and \\ Institute of Veterinary Science, \\ Chungnam National University, Daejeon \\ ${ }^{2}$ Herbal Medicine Formulation Research \\ Group, Korea Institute of Oriental \\ Medicine, Deajeon \\ ${ }^{3}$ Department of Anatomy, The Catholic \\ University of Korea, Seoul, Korea
}

\section{Abstract}

A defect in Klotho gene expression in the mouse results in a syndrome that resembles rapid human aging. In this study, we investigated the detailed distribution and the time of the first appearance of Klotho in developing and adult mouse kidney. Kidneys from 16(F16), 18-(F18) and 20-day-old (F20) fetuses, 1- (P1), 4- (P4), 7- (P7), 14- (P14), and 21-dayold (P21) pups and adults were processed for immunohistochemistry and immunoblot analyses. In the developing mouse kidney, Klotho immunoreactivity was initially observed in a few cells of the connecting tubules (CNT) of 18-day-old fetus (F) and in the medullary collecting duct (MCD) and distal nephron of the F16 developing kidney. In F20, Klotho immunoreactivity was increased in CNT and additionally observed in the outer portion of MCD and tip of the renal papilla. During the first 3 weeks after birth, Klotho-positive cells gradually disappeared from the MCD due to apoptosis, but remained in the CNT and cortical collecting ducts (CCD). In the adult mouse, the Klotho protein was expressed only in a few cells of the CNT and CCD in cortical area. Also, Klotho immunoreactivity was observed in the aquaporin 2-positive CNT, CCD, and $\mathrm{NaCl}$ cotransporter-positive distal convoluted tubule (DCT) cells and type B and nonA-nonB intercalated cells of CNT, DCT, and CCD. Collectively, our data indicate that immunolocalization of Klotho is closely correlated with proliferation in the intercalated cells of CNT and CCD from aging, and may be involved in the regulation of tubular proliferation.

\section{Introduction}

The Klotho gene, named after a Greek goddess who spins the thread of life, was initially identified in 1997 as a factor mutated in the Klotho mouse that exhibited multiple disorders resembling human premature-aging syndrome. ${ }^{1}$ The gene plays a critical role in regulating aging and development of age-related diseases in mammals. Loss of Klotho can result in multiple aging-like phenotypes, ${ }^{1}$ while its overexpression extends the lifespan by $20-30 \%{ }^{2}$ Although Klotho participates in phenotypic alterations in various organs, the gene is highly expressed in the kidney and associated with elevated serum levels of 1,25dihydroxyvitamin D3, phosphate and calcium through fibroblast growth factor 23 (FGF23) in aging-like phenotypes in mice. ${ }^{3,4}$

Recent studies have shown that renal Klotho gene expression is regulated in animal models of metabolic disease and humans with chronic renal failure (CRF). Klotho transcription is significantly reduced in the kidneys of all CRF patients, ${ }^{5}$ and dietary inorganic phosphate restriction induces expression. Mitani $e t$ $a l .{ }^{6}$ investigated the role of angiotensin II in regulation of renal Klotho gene expression in the kidney. Downregulation of renal Klotho exacerbates ischemic acute renal failure (ARF). ${ }^{7}$ Conversely, overexpression of Klotho leads to an extended lifespan and retarded aging process through a mechanism possibly involving the induction of insulin and oxidative stress resistance. ${ }^{2}$ These findings collectively support the theory that Klotho plays an important role in aging and senescence-related disorders. Several phenotypes of Klotho mutant mice developed a syndrome resembling human aging, characterized by shortened life-span, growth retardation, arteriosclerosis, skin and muscle atrophy, and osteoporosis. In addition, Klotho functions as a co-receptor for fibroblast growth factor 23 (FGF23), which downregulates the expression of 1,25dihydroxyvitamin D3 and phosphate reabsorption. ${ }^{8,9}$ An earlier study reported that Klotho enhances resistance to oxidative stress. ${ }^{5}$ Furthermore, Klotho may protect the cardiovascular system by increasing nitric oxide (NO) production, ${ }^{10}$ and has been shown to inhibit insulin and insulin-like growth factor 1 (IGF-1) signaling pathways. ${ }^{11}$ The mechanisms underlying the involvement of this gene in multiple biological processes have been extensively investigated. ${ }^{12}$ While it is established in adult animals that Klotho protein is expressed in the distal convoluted tubule of kidney, little is known about the expression and the precise distribution of Klotho in the kidney, and there is no information at all about its distribution in the correct tubules and positive cell types in developing mouse kidney. Accordingly, the present study was designed to establish the timings of expression and patterns of distribution of Klotho in the developing and adult mouse kidney.
Correspondence: Dr. Ju-Young Jung, Department of Veterinary Medicine, Chungnam National University, 220 Gung-dong, Yusung-gu, Daejeon 305-764, Korea.

Tel. +82.42.8218899-7902 - Fax: +82.42.8217926. E-mail: jyjung@cnu.ac.kr, cozy37@gmail.com

Key words: Klotho, developing kidney, aging, intercalated cell, tubular proliferation.

Acknowledgments: this research was supported by Basic Science Research Program through the National Research Foundation of Korea (NRF) funded by the Ministry of Education, Science and Technology (2011-0023232).

Contributions: JHS and MYL contributed equally to this work.

Conflict of interest: the authors declare no conflict of interests.

Received for publication: 1 August 2013. Accepted for publication: 2 December 2013.

This work is licensed under a Creative Commons Attribution NonCommercial 3.0 License (CC BYNC 3.0).

(C) Copyright J.H. Song et al., 2014

Licensee PAGEPress, Italy

European Journal of Histochemistry 2014; 58:2256 doi:10.4081/ejh.2014.2256

\section{Materials and Methods}

\section{Animals}

Specific pathogen-free inbred C57BL/6 mice routinely screened serologically for relevant respiratory pathogens were purchased from Daehan Biolink Co. Ltd. (Seoul, Korea). Mice were maintained in an animal facility under standard laboratory conditions, and provided water and standard chow ad libitum. All experimental procedures were performed in accordance with the NIH Guidelines for the Care and Use of Laboratory Animals, and animal handling followed the dictates of the National Animal Welfare Law of Korea.

\section{Preparation of kidneys}

Mice were anesthetized with an intraperitoneal injection of pentobarbital sodium (50 $\mathrm{mg} / \mathrm{kg}$ ), perfused transcardially with phosphate buffered saline (PBS) at an osmolality of $298 \mathrm{mOsmol} / \mathrm{kgH}_{2} \mathrm{O}(\mathrm{pH} 7.4$ ) to rinse away blood, and fixed with periodate-lysine- $2 \%$ paraformaldehyde (PLP) solution. Kidneys were subsequently dissected and immersed in the same fixative overnight at $4^{\circ} \mathrm{C}$. Sections of tissue were cut transversely through the entire kidney at a thickness of $50 \mu \mathrm{m}$ using a vibratome (Pelco 102, series 1000, Technical 
Products Int., St. Louis, M0, USA). Prenatal kidneys were obtained from fetuses on days (F) 16, F18, F19 and F20, and postnatal kidneys from postnatal days (P) 1, P4, P7, P14, and P21, and adult animals. Adult male mouse (8-week) kidneys $(n=8)$ were used as the positive control in immunohistochemical studies. To determine the number of proliferating kidney cells, $20 \mathrm{mg} / \mathrm{kg}$ 5-bromo-2-deoxyuridine (BrdU; Boehringer, Mannheim, Germany) was subcutaneously injected four times at $8 \mathrm{~h}$ intervals over a total period of $24 \mathrm{~h}$, and the kidneys preserved $2 \mathrm{~h}$ after the last injection of BrdU.

\section{Antibodies}

Alpha-klotho immunoreactivity was detected using a specific rabbit polyclonal antibody (1:1000 dilution, Alpha Diagnostic Inc., San Antonio, TX, USA). Thiazide-sensitive $\mathrm{NaCl}$ cotransporter (NCC) expression was detected using a specific affinity-purified rabbit polyclonal antibody (courtesy of Dr. Soren Nielsen). Aquaporin 2 (AQP2), BrdU, pendrin, and $\mathrm{H}^{+}$-ATPase expressions were detected using a rabbit polyclonal antibody against AQP2 (Chemicon, Temecula, CA, USA), mouse monoclonal antibody against BrdU (Dako, Glastrup, Denmark), and rabbit polyclonal antibody against pendrin and $\mathrm{H}^{+}$-ATPase activity (courtesy of Dr. Soren Nielsen).

\section{Immunohistochemistry}

Vibratome sections (50 $\mu \mathrm{m}$ thick) through the entire kidney were obtained from all animals and processed for immunohistochemistry using an indirect immunoperoxidase method. All sections were washed three times in PBS containing $50 \mathrm{mM} \mathrm{NH}_{4} \mathrm{Cl}$ for $15 \mathrm{~min}$. Before incubation with the primary antibodies, sections were pretreated with a graded series of ethanol or left untreated and incubated for $4 \mathrm{~h}$ with PBS containing $1 \%$ BSA, $0.05 \%$ saponin, and $0.2 \%$ gelatin. Tissue sections were incubated overnight at $4{ }^{\circ} \mathrm{C}$ with a rabbit polyclonal Klotho antibody (1:1000) diluted in 1\% BSA in PBS (solution A). Control incubations were made using solution A without the primary antibody. After several washes in PBS containing $0.1 \% \mathrm{BSA}, 0.05 \%$ saponin, and $0.2 \%$ gelatin (solution B), tissue sections were incubated for $2 \mathrm{~h}$ with horseradish peroxidase-conjugated donkey anti-rabbit IgG Fab fragment (Jackson ImmunoResearch Laboratories, West Grove, PA, USA) diluted 1:100 in PBS containing $1 \%$ BSA. Tissues were initially rinsed in solution $\mathrm{B}$, and subsequently in $0.05 \mathrm{M}$ Tris buffer ( $\mathrm{pH}$ 7.6). To detect horseradish peroxidase, sections were incubated in $0.1 \% 3,3$ 'diaminobenzidine (DAB) in $0.05 \mathrm{M}$ Tris buffer for $5 \mathrm{~min} . \mathrm{H}_{2} \mathrm{O}_{2}$ was added to a final concentration of $0.01 \%$ and incubation continued for 10 min. Sections were washed three times with $0.05 \mathrm{M}$ Tris buffer, dehydrated in a graded series of ethanol, and embedded in Poly/Bed 812 resin (Polysciences, Warrington, PA, USA).

\section{Double labeling of $1 \mu \mathrm{m}$ Epon 812- embedded sections}

To identify each of cell types, we used double labeling techniques. From flat-embedded vibratome sections of kidneys processed for immunohistochemical identification of type $B$ and nonA-nonB-intercalated cells using Klotho protein, each region was excised and glued onto an empty block of Epon-812. Two consec-

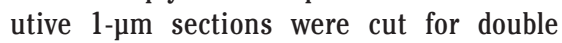
immunolabeling of $\mathrm{H}^{+}$-ATPase and pendrin. Sections were treated for 15 min with a mixture of saturated sodium hydroxide and absolute ethanol (1:1) to remove the resin. After three brief rinses in absolute ethanol, sections were hydrated with graded ethanol and rinsed in tap water. Next, sections were rinsed with PBS, incubated in normal donkey serum for $1 \mathrm{~h}$ and subsequently incubated overnight at $4{ }^{\circ} \mathrm{C}$ with antibodies to $\mathrm{H}^{+}$-ATPase and pendrin (diluted 1:200 and 1:500 in PBS). After washing in PBS, sections were incubated for $2 \mathrm{~h}$ in peroxidase-conjugated donkey antigoat or rabbit IgG (Fab fragment) and rewashed with PBS. For detection of $\mathrm{H}^{+}$-ATPase and pendrin, Vector SG (Vector Laboratories, Burlingame, CA, USA) was used as the chromogen and produced a gray-blue color that was easily distinguished from the brown label produced by DAB in the first immunolocalization procedure for Klotho with the pre-embedding method. Sections were washed in distilled water, dehydrated with graded ethanol and xylene, mounted in balsam, and examined using light microscopy.

\section{Double or triple labeling of wax- embedded sections}

Slices of PLP-fixed kidney tissue were dehydrated and embedded in polyester wax, and two or three consecutive $2 \mu \mathrm{m}$ sections cut and mounted on gelatin-coated glass slides. The sections were dewaxed with xylene and ethanol and treated with methanolic $\mathrm{H}_{2} \mathrm{O}_{2}$ for $30 \mathrm{~min}$ after rinsing in tap water. Prior to incubation with the primary antibody, sections were permeabilized via incubation for $15 \mathrm{~min}$ in $0.5 \%$ Triton X-100 in PBS, subsequently blocked with normal goat serum (diluted 1:10 in PBS) for $1 \mathrm{~h}$, and incubated overnight at $4{ }^{\circ} \mathrm{C}$ with rabbit antiserum against AQP2 (1:500) and NCC (1:500) or mouse antiserum against BrdU (1:100) diluted in PBS. Next, sections were rinsed in PBS and incubated for $2 \mathrm{~h}$ in peroxidase-conjugated donkey anti-rabbit or donkey anti-mouse IgG (Jackson ImmunoResearch Laboratories, West Grove, PA, USA), followed by peroxidase-substrate solution, a mixture of $0.05 \% 3,3$ 'diaminobenzidine and $0.01 \% \mathrm{H}_{2} \mathrm{O}_{2}$, for $5 \mathrm{~min}$ at room temperature. Sections were rinsed in tap water, dehydrated with graded ethanol and xylene, mounted in balsam, and examined using light microscopy.

\section{Quantification of BrdU- positive/Klotho-positive cells}

Klotho-positive tubules were counted on 2$\mu \mathrm{m}$ wax sections of kidneys from three P4 and P7 animals. In the $2-\mu \mathrm{m}$ serial sections, BrdUlabeled nuclei were counted and expressed as a percentage of the total number of Klotho-positive tubules, respectively, estimated in the different tubule segments for each animal. Values are expressed as a percentage of Klotho-positive tubules in the respective segments, and presented as means \pm standard deviations.

\section{Western blot analysis}

Kidneys from five animals in each age group were homogenized in lysis buffer containing 20 mM Tris.HCl, 1\% Triton X-100, 150 mM sodium chloride, $0.5 \%$ sodium deoxycholate, $0.1 \%$ sodium dodecyl sulfate, $0.02 \%$ sodium azide, $1 \mathrm{mM}$ EDTA, $10 \mathrm{mM}$ leupeptin, and $1 \mathrm{mM}$ phenylmethylsulfonyl fluoride. The homogenate was centrifuged at $3000 \mathrm{~g}$ for $20 \mathrm{~min}$ at $4^{\circ} \mathrm{C}$. After determination of protein concentration in the supernatant with the Coomassie method (Pierce, Rockford, IL, USA), loaded samples (30 $\mu \mathrm{g} /$ lane) were subjected to electrophoresis on sodium dodecyl sulfate-polyacrylamide gels under reducing conditions. Proteins were transferred via electroelution to nitrocellulose membranes that had been blocked with 5\% nonfat dry milk in PBS-T (0.1\% Tween-20 in $0.01 \mathrm{M}$ PBS, pH 7.4) for $30 \mathrm{~min}$ at room temperature, and incubated overnight at $4{ }^{\circ} \mathrm{C}$ with affinitypurified anti-Klotho antibodies (1:5000). Membranes were washed in several changes of PBS-T and incubated for $2 \mathrm{~h}$ with horseradish peroxidase-conjugated donkey anti-rabbit IgG (1:1000). After a final wash, antibody labeling was visualized using an enhanced chemiluminescence system (Amersham Life Sciences, Buckinghamshire, UK) at room temperature.

\section{Statistical analysis}

Data obtained from quantitative analyses were analyzed with one-way ANOVA to determine statistical significance. Bonferroni's test was used for post-hoc comparisons. P values below 0.05 or 0.01 were considered statistically significant.

\section{Results \\ Immunolocalization of Klotho in adult mouse kidney}

Light microscopy assessment of $50 \mu \mathrm{m} \mathrm{sec}$ tions revealed intense Klotho immunolocaliza- 
tion in the cortex (CO) and weak in the outer medulla $(\mathrm{OM})$. There are no Klotho immunolabeling in the inner medulla (Figure $1 \mathrm{~A}$-a). Higher magnifications of the $\mathrm{CO}$ revealed that Klotho was most strongly localized in the some tubular profiles around glomerulus of superficial cortex (Figure 1 A-b) and most inner cortex (Figure $1 \mathrm{~A}-\mathrm{c}$ ). We observed no immunoreacticity in the glomerular and proximal segments in the cortex (Figure $1 \mathrm{~A}-\mathrm{b}, \mathrm{c}$ ). As the results of immunoblotting, the Klotho protein was detected in the renal $\mathrm{CO}$ and $\mathrm{OM}$ of adult mice, but not IM (Figure 1B). To determine the precise location of Klotho in cortical tubules, we examined $5 \mu \mathrm{m}$ wax sections of cortex. Klotho immunoreactivity was founded in the distal convoluted tubule (DCT), connecting tubule (CNT) and cortical collecting duct (CDD) in the adult renal cortex (Figure 2). In these tubules, Klotho-negative cells could be detected among the Klotho-positive cells (Figure 2 B,C).

To identify whether Klotho was expressed in the CCD, serial sections were cut and double labeled Klotho and AQP-2. AQP2 was specifically detected in the apical membranes of cells of the cortical, medullary, and inner medullary collecting ducts. At DIC of higher magnification, AQP2 was expressed in the principal cells of the CCD, but not in the intercalated cells (Figure 3B). In contrast, Klotho was detected AQP-2 negative intercalated cells (Figure 3A). Light microscopy analysis was employed to identify the expressing Klotho in the CNT and CCD. Specifically, plastic sections were immunolabeled with a specific antibody against Klotho using a pre-embedding method, followed by labeling of two consecutive $1 \mu \mathrm{m}$ sections of the same tissue using a postembedding method. The first section was used for the detection of $\mathrm{H}^{+}$-ATPase (Figure 4A), and the second for the detection of pendrin (Figure 4B) immunoreactivity. Subtypes of intercalated cells were easily identified by their pattern of immunostaining for $\mathrm{H}^{+}$ATPase and pendrin using double-labeling procedures on $1 \mu \mathrm{m}$ thick sections from adult mouse kidneys. Type A intercalated cells, identified by the presence of apical $\mathrm{H}^{+}$-ATPase, constituted a major proportion of the intercalated cell population in the DCT, CNT, and CCD in adult mouse kidneys. Type B intercalated cells, characterized by basolateral and/or diffuse localization of $\mathrm{H}^{+}$-ATPase and apical pendrin immunostaining, were frequently observed in the CCD. NonA-nonB type intercalated cells were found in the apical membrane, and contained both $\mathrm{H}^{+}$-ATPase and pendrin. Numerous Klotho-labeled cells were located among the intercalated cells of CNT and CCD. Klotholabeled cells were observed among apical pendrin/basolateral $\mathrm{H}^{+}$-ATPase positive-type B cells (Figure 4; open arrows), apical pendrin
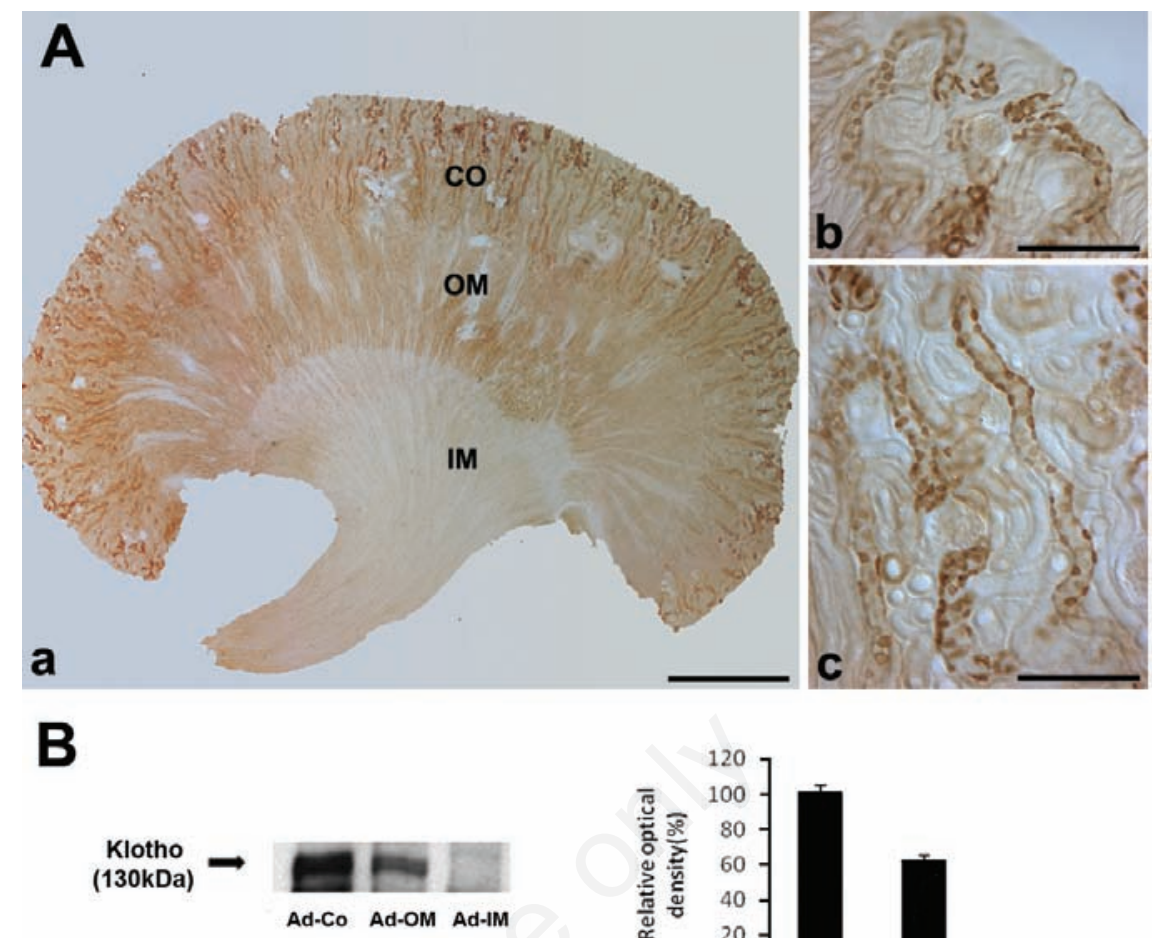

a

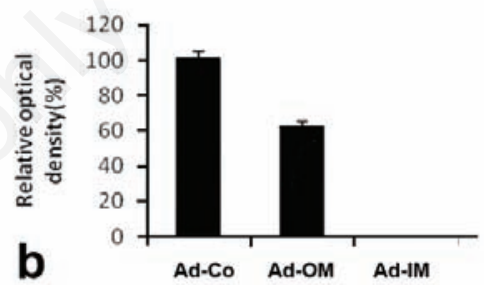

Figure 1. A) Light micrographs of $50 \mu \mathrm{m}$ thick vibratome sections from the adult control mouse kidney illustrating single immunostaining for Klotho. a) Klotho immunoreactivity is located in the Cortex $(\mathrm{Co})$ and outer medulla $(\mathrm{OM})$; no Klotho immunostaining is observed in the inner medulla (IM). b,c) Higher magnification of Co; Klotho protein is expressed in cells of the CNT and CCD; scale bars: a) $100 \mu \mathrm{m} ; \mathrm{b}, \mathrm{c}) 10 \mu \mathrm{m}$. B and a) Western blot demonstrating Klotho protein expression in the Co and OM of adult mouse kidney; protein $(30 \mu \mathrm{g})$ was applied to each lane. b) The relative optical density of the immunoblot band is presented $(P<0.05)$.
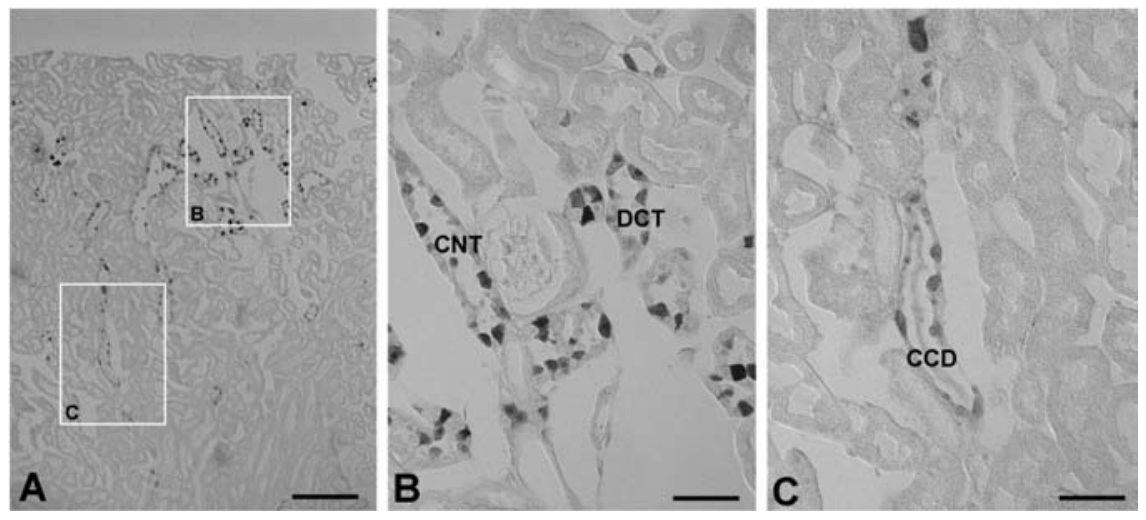

Figure 2. A) Light micrographs of $5 \mu \mathrm{m}$ wax sections from kidneys of adult mouse illustrating immunostaining for Klotho. B) Klotho immunoreactivity is located in the connecting tubule (CNT) and distal convoluted tubule (DCT) of cortex; C) Klotho immunoreactivity is located in the some cells of cortical collecting ducts (CCD). Scale bars: $5 \mu \mathrm{m}$. 
and $\mathrm{H}^{+}$-ATPase/basolateral pendrin and $\mathrm{H}^{+-}$ ATPase-negative nonA-nonB intercalated cells (Figure 4; arrows).

\section{Immunolocalization of Klotho in the developing mouse kidney}

At F16, Klotho immunoreactivity was observed across a broad area, especially in the medullary collecting duct (MCD) and distal nephron of the developing fetal kidney (Figure $5 \mathrm{~A}, \mathrm{C})$. In the 19-day-old fetal kidney, Klotho immunoreactivity is increased in the distal

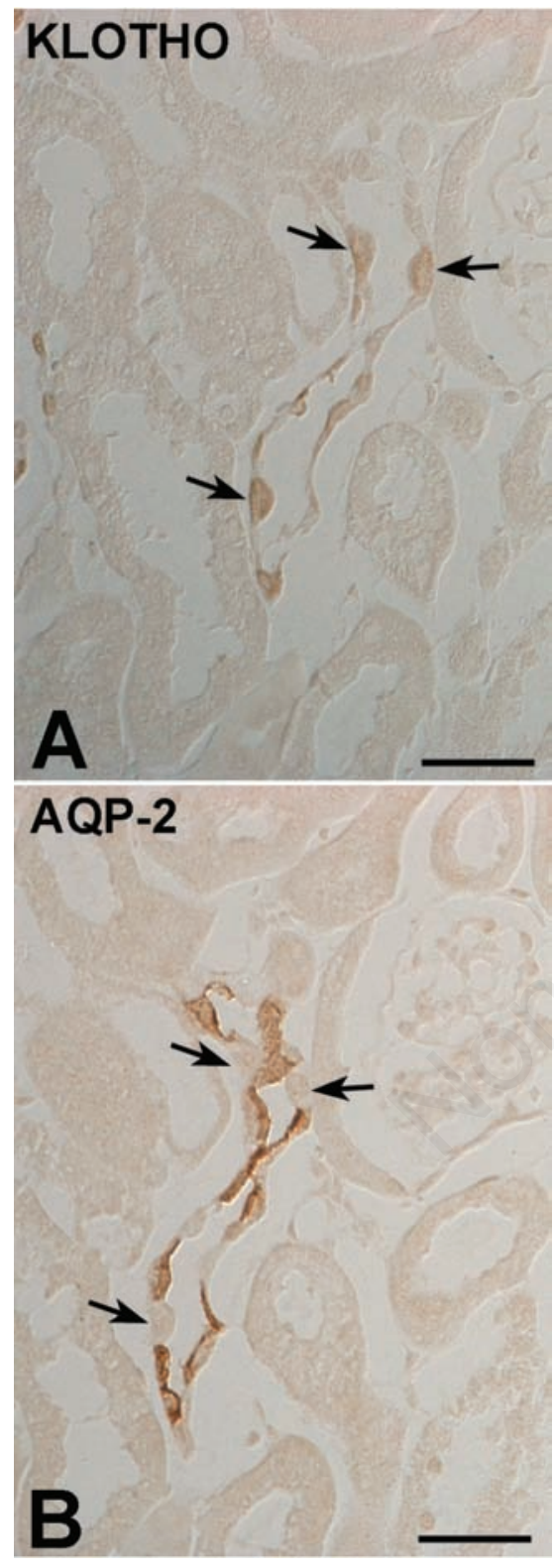

Figure 3. DIC micrographs of the cortex from adult mouse kidney. Illustrating serial immunostaining for (A) Klotho and (B) AQP2 in the cortical collecting duct. AQP2-negative cells (arrows) are observed in the intercalated cells of the CCD. Scale bars: $2 \mu \mathrm{m}$. nephron and is also observed in the outer portion of the MCD and in the tip of the renal papilla (Figure 5B). Intense Klotho immunoreactivity is observed in a few cells of the distal nephron (Figure 5 D). At the P1 stage, Klotho
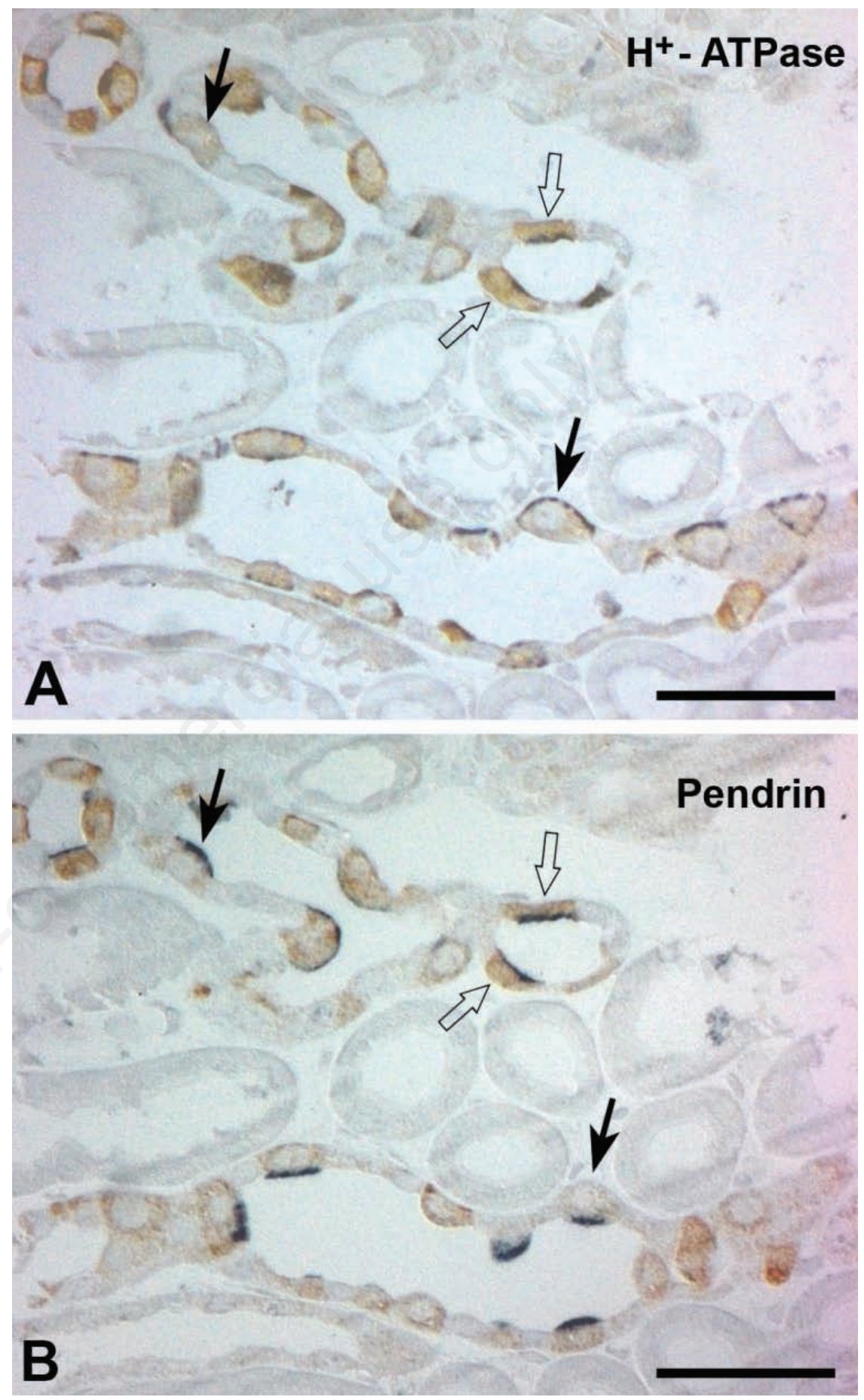

Figure 4. Light micrographs of consecutive 1- $\mu \mathrm{m}$ thick sections from adult kidneys, illustrating double immunostaining for Klotho (brown) and H+-ATPase (blue), (A) klotho (brown) and (B) pendrin (blue); numerous Klotho-labeled cells are located in the intercalated cells of the CNTs and CCDs. Klotho-labeled cells are observed in apical pendrin/basolateral $\mathrm{H}+$-ATPase positive type B intercalated cells (arrows); also expressed in the apical pendrin and $\mathrm{H}+-\mathrm{ATPase} / \mathrm{basolateral}$ pendrin and $\mathrm{H}+-\mathrm{ATPase}$ negative nonAnonB intercalated cells (arrows). Scale bars: 5 m. 
was very similar to that observed at P4 kidney, but the Kloth-positive cells in the cortex were more numerous and more intensely immunoreactive (Figure 6C). At P14 and At P21, intense Kloth-positive tubular profiles could be found in the outer cortex and had begun disappearing in the inner medulla (Figure 6 D,E). By P21, the distribution of Klotho had spread to the inner stripe of the outer medulla with a distribution similar to that seen in adult kidney. No labeled profiles were found in the IM (Figure 6E).

To determine the precise location of Klotho in the cortical tubule, immunoreactivity was assessed via $\mathrm{AQP} 2$ and NCC localization in consecutive $2 \mu \mathrm{m}$ thick sections from the kidneys of P7. AQP2 expression was specifically detected in the apical membranes of cells of the CCD. NCC was initially identified at the distal end of the nascent DCT. At higher magnifications, Klotho immunoreactivity was observed in the AQP2-positive CNT, CCD, and NCC-positive DCT (Figure 7), with intensity in developing DCT, CNT, and CCD of P4 and P7 cortex, and in the majority of cells of the DCT, CNT, and CCD of P14 and P21 kidneys (data not shown). Cell proliferation was determined through detecting incorporation of BrdU into the DNA of dividing cells, followed by immunohistochemical detection using a double labeling procedure for the detection of BrdU (Figure 8B,D) and Klotho (Figure 8A,C) immunoreactivity in serial sections. At higher magnification of the $2 \mu \mathrm{m}$ sections, Klotho immunoreactivity was observed in BrdU-positive cells in P4 (Figure 8A,B) and P7 (Figure $8 \mathrm{C}, \mathrm{D})$ kidneys. Numerous BrdU-labeled cells were located in the nephrogenic zone, and a few BrdU-labeled nuclei were observed in the Klotho-positive cells (Figure 8).

In immunoblotting experiments, Klotho was expressed from F16 kidneys. Densitometric analysis of the relative abundance of Klotho protein revealed a gradual increase from F16 to P1 in whole kidney. After birth, Klotho protein was maintained its level during 3 weeks after birth in the cortex. In contrast, a rapid decrease in expression at P14 and P21 in inner medulla (Figure 9). The pattern of relative abundance of Klotho protein was similar to that observed in immunohistochemical analysis.

\section{Discussion}

The functional integrity of the kidney depends on its normal development and physiological cell turnover. The Klotho gene encodes a $130 \mathrm{kDa}$ transmembran e protein that shares sequence homology with $\beta$-glucosidase. ${ }^{1}$ Recent reports have shown that Klotho is involved in calcium homeostasis, along with several other activities. In addition, Klotho influences intracellular signaling pathways, including those of cAMP, protein kinase $\mathrm{C}$, and Wnt. ${ }^{9,13}$ However, the expression patterns and role of the protein have not been described in the developing mouse kidney. In the present study, we assessed the timings of expression and immunolocalization patterns of Klotho in the developing and adult mouse kidney, with a
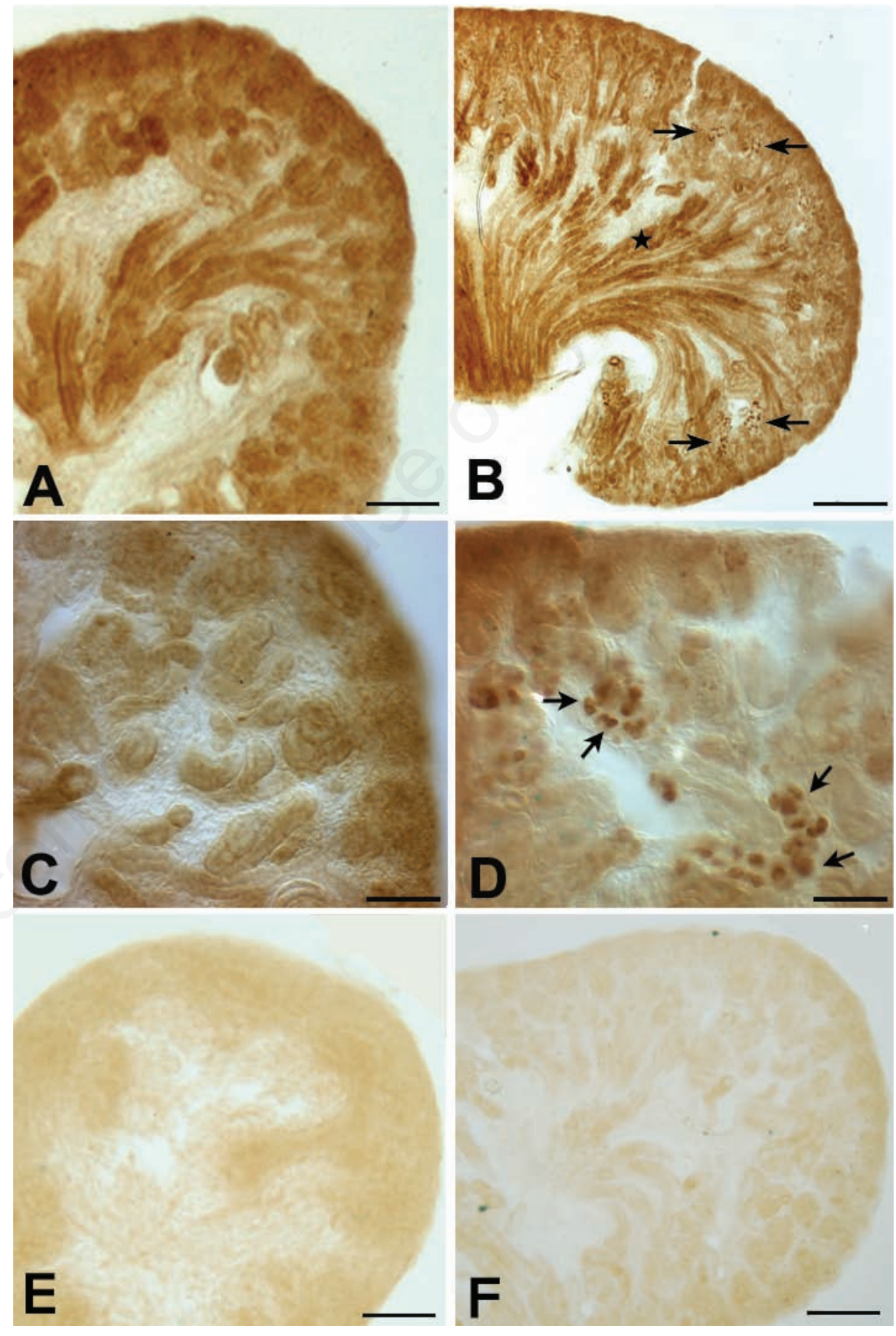

Figure 5. Light micrographs of 50- $u$ m thick vibratome sections from 16-day-old (A, C) and 19-day-old (B, D) fetal mouse kidneys, illustrating Klotho immunostaining. C, D) Higher magnification of A and B, respectively. A, C) Klotho immunostaining is observed in a broad area of the 16-day-old fetus. B) In the 19-day-old fetal kidney, Klotho immunoreactivity is increased in the distal nephron (arrows) and is also observed in the outer portion of the MCD (star) and in the tip of the renal papilla. D) Klotho immunoreactivity is observed in a few cells of the CNT. E) Negative control with no Klotho antibody in F16 kidney. F) Negative control with no Klotho antibody in F19 kidney. Scale bars: A,B) $100 \mu \mathrm{m}$; C,D) $10 \mu \mathrm{m}$. 


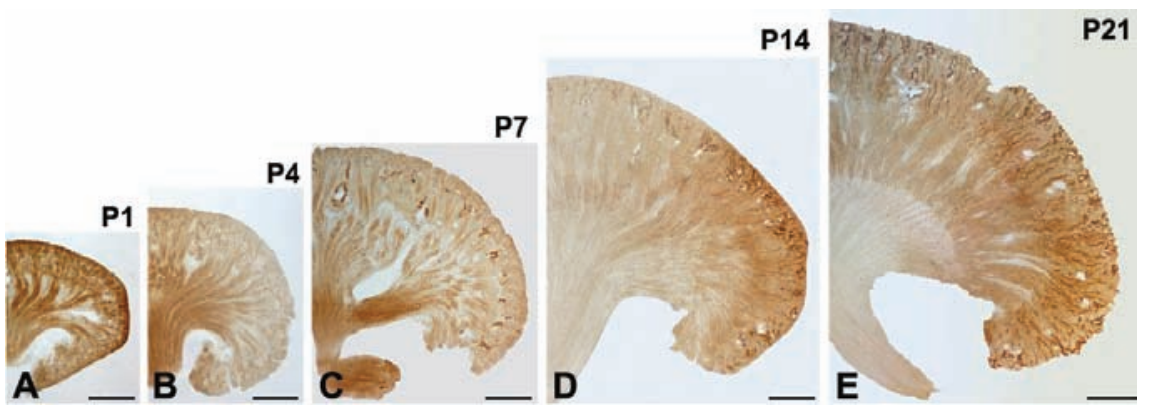

Figure 6. Light micrographs of $50-\mu \mathrm{m}$ thick vibratome sections from the kidneys of mouse pups at post-natal days 1 (A), 4 (B), 7 (C), 14 (D), and 21 (E); medullary Klotho immunoreactivity was gradually decreased; in contrast, cortical Klotho immunoreactivity gradually increases after birth; note a remarkable increase in the immunoreactivity of Klotho in the Co. Scale bars: $100 \mu \mathrm{m}$.

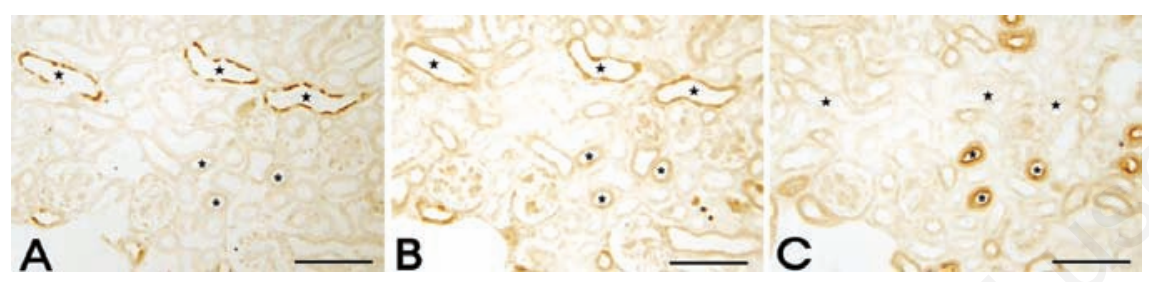

Figure 7. Light micrographs of consecutive $2-\mu \mathrm{m}$ thick sections from kidneys of mouse pups at postnatal day 7 , illustrating immunostaining of AQP2, Klotho, and NCC. A) Apical AQP2-positive immunoreactivity identifies the principal cells of the CD (stars). B) Klotho is expressed in the CNT, DCT (asterisks), and CCD (stars). C) Immunoperoxidase labeling of NCC in the DCT (asterisks) of the renal cortex. Scale bars: $20 \mu \mathrm{m}$.

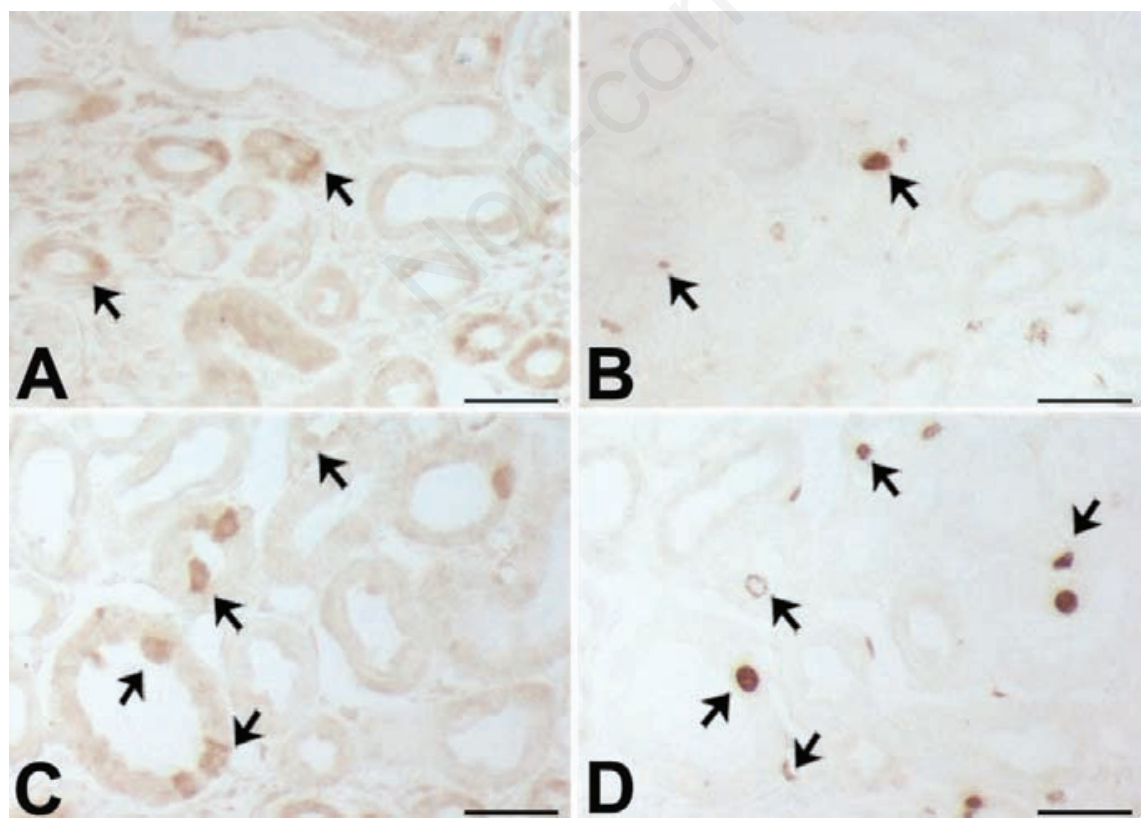

Figure 8. Light micrographs of consecutive $2-\mu \mathrm{m}$ thick sections from mouse cortex at post-natal days $4(\mathrm{~A}, \mathrm{~B})$ and $7(\mathrm{C}, \mathrm{D})$, illustrating labeling $(\mathrm{A}, \mathrm{C})$ Klotho and $(\mathrm{B}, \mathrm{D}) \mathrm{BrdU}$ positivity; some BrdU-labeled cell are observed among the Klotho-positive tubules (arrows). Scale bars: $5 \mu \mathrm{m}$. view to establishing its possible function.

Klotho immunoreactivity was initially observed in uriniferous tubules in F16, and the intensity of labeling gradually increased in the $\mathrm{CO}$, along with a gradual decrease in the IM during the first 3 weeks after birth. At P1, Klotho-positive tubular cells appeared in a broad area of $\mathrm{CO}, \mathrm{OM}$, and IM, which were gradually increased from P4 to P7. In P14 kidney, Klotho immunolocalization was increased principally in the $\mathrm{CO}$ and $\mathrm{OM}$, but decreased in the IM. In rats and mice, the first generation of nephrons becomes functional around birth while branching morphogenesis of the CCD and tubulogenesis of the last nephron generation are completed around post-natal (P) day P7. ${ }^{14}$ In our study, from P1 to P14, Klotho immunoreactivity appeared in the intercalated cells of the CNT, DCT, and CCD, but not IM at P14 and P21. Klotho expression patterns in the $\mathrm{CO}$ and $\mathrm{OM}$ at P14 and P21 were similar to those in adult mouse kidney.

Anatomically, the nephron includes the glomerulus, proximal and distal convoluted tubules, and the loop of Henle. The loop of Henle is formed as an outgrowth from the proximal and distal tubule anlage of the nephron, close to the vascular pole of the glomerulus. Concomitant with the growth and development of the renal papilla, loops of Henle grow and descend from the glomerulus towards the papilla tip. ${ }^{15}$ Numerous mitoses have been reported in the anlage of the loop of Henle, ${ }^{16}$ and cell proliferation in the loop of Henle occurs mainly in the $0 \mathrm{M}$ and medullary rays in the cortex 5-7 days after birth. A rapid increase in Klotho expression was observed in the developing kidney at P7, similar to that reported in a previous study. ${ }^{15}$ In the current investigation, we examined the colocalization of Klotho, AQP2 and NKCC2 in the kidneys of mice to determine whether the medullary tubules were maturing thin descending limbs of Henle. The collecting duct is composed of two structurally and functionally distinct cell types, specifically, principal and intercalated cells. ${ }^{17}$ These cells play an important role in water reabsorption and acid-base homeostasis. AQP2 is a specific marker for the principal cells of the cortical collecting tubules and cortical and medullary collecting ducts. ${ }^{18}$ Klotho immunoreactivity was observed in the AQP2positive CNT, CCD, and NCC-positive DCT cells in the adult kidney and neonatal kidney. The results indicate that Klotho is associated with water reabsorption and acid-base homeostasis regulation.

Intercalated cells play a major role in proton and bicarbonate secretion in the CD, and constitute between $30 \%$ and $40 \%$ of cells in the CNT and CCD. ${ }^{19}$ Type A intercalated cells secrete protons via a vacuolar-type $\mathrm{H}^{+}$-ATPase that is located in the apical plasma membrane 
and apical tubulovesicles. ${ }^{20}$ Bicarbonate is reabsorbed by a band 3-like $\mathrm{Cl} / \mathrm{HCO}^{-}$exchanger located in the basolateral plasma membrane. ${ }^{21}$ Type B intercalated cells secrete bicarbonate via a process mediated by an apical $\mathrm{Cl}^{-}$ /HCO3- exchanger distinct from the band 3-like anion exchanger present in the basolateral plasma membrane of type A cells. ${ }^{22}$ NonA-nonB intercalated cells contain a vacuolar-type $\mathrm{H}^{+}-$ ATPase in the apical plasma membrane, similar to type A intercalated cells, but display no basolateral band 3 immunoreactivity. ${ }^{1}$ In the adult kidney, Klotho was mainly expressed in $\mathrm{CO}$, where it was detected in type B-intercalated cells and nonA-nonB intercalated cells of the CNT, DCT, and CCD. Klotho protein was additionally detected in the CCD, but no immunoreactivity was observed in the IM. Klotho was expressed in the type B and nonAnonB intercalated cells of CNT, DCT, and CCD of adult mouse kidney. To identify the Klothopositive cells undergoing proliferation, a multiple labeling procedure was used for detection of BrdU. Interestingly, BrdU labeling was observed among the Klotho-positive tubules undergoing proliferation or newly formed uriniferous tubules.

Aging in most species is associated with impaired adaptive and homeostatic mechanisms, leading to susceptibility to environmental or internal stresses, along with increasing rates of disease. Renal aging is associated with renal disease and nonrenal clinical complications in humans. ${ }^{23}$ Klotho is a recently identified anti-aging gene. Deletion of Klotho (Kl-/-) results in extensive phenotypes resembling human aging, including shortened life span, growth retardation, infertility, arteriosclerosis, skin and muscle atrophy, osteoporosis, and pulmonary emphysema. ${ }^{1}$ Conversely, overexpression of the Klotho gene extends the life span in mice. ${ }^{2}$ The age-related decline in renal function is attributed, at least in part, to progressive loss of functioning nephrons, which eventually results in a decrease in the glomerular filtration rate. The Klotho protein is predominantly expressed in renal tubule epithelial cells. ${ }^{3}$ Klotho reduces apoptosis in acute experimental ischemic renal failure, ${ }^{7}$ and its production is severely inhibited in human chronic kidney failure. ${ }^{24}$ Moreover, Klotho deficiency causes kidney damage ${ }^{25}$ suggesting that the protein is essential for maintaining normal kidney structure and function. Also, it is reported that restoration of Klotho gene expression induces apoptosis and autophagy in gastric cancer cells ${ }^{26}$ and inhibits growth and promotes apoptosis in humang lung cancer. ${ }^{27}$ In the present study, Klotho immunoreactivity was initially detected in the F16 mouse kidney, and exhibited a gradual increase in intensity after birth. This novel finding suggests that the aging-related cognitive impairment, in parallel with kidney aging, is associated with suppression of Klotho expression. Based on the results, we propose that Klotho is involved in the regulation of tubular proliferation.

\section{References}

1. Kuro-0 M, Matsumura Y, Aizawa H, Kawaguchi H, Suga T, Utsugi T, et al. Mutation of the mouse klotho gene leads to a syndrome resembling ageing. Nature 1997;390:45-51.

2. Kurosu H, Yamamoto M, Clark JD, Pastor JV, Nandi A, Gurnani P, et al. Suppression of aging in mice by the hormone Klotho. Science 2005;309:1829-33.

3. Yoshida T, Fujimori T, Nabeshima Y. Mediation of unusually high concentra-

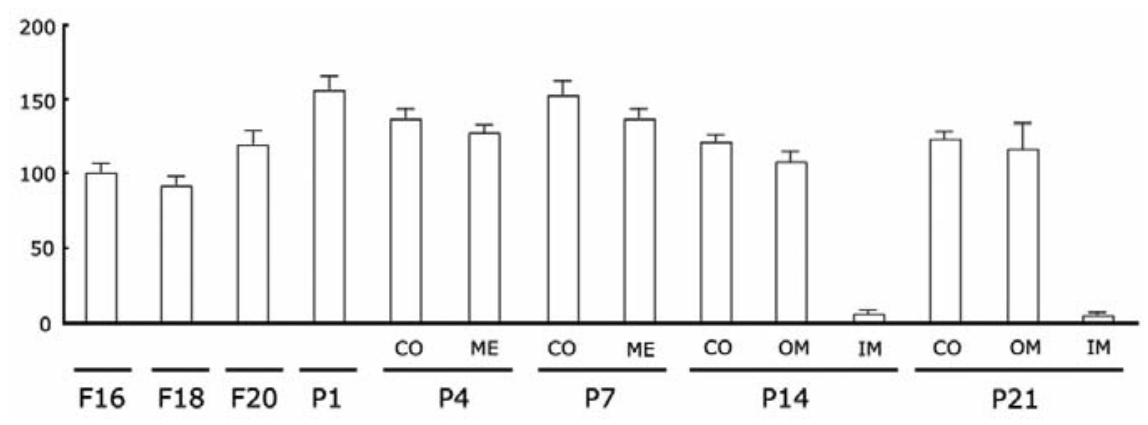

Figure 9. Densitometric evaluation of Western blot analyses $(n=5)$ demonstrating the expression of the $130 \mathrm{kDa}$ Klotho protein in developing mouse kidneys; a gradual increase in the relative abundance of Klotho protein was observed from F16 to P1 in whole kidney; after birth, a strong decrease in Klotho expression was found, at P14 and P21, in inner medulla (IM). tions of 1,25-dihydroxyvitamin $\mathrm{D}$ in homozygous klotho mutant mice by increased expression of renal 1alphahydroxylase gene. Endocrinology 2002; 143:683-9.

4. Kurosu H, Ogawa Y, Miyoshi M, Yamamoto M, Nandi A, Rosenblatt KP, et al. Regulation of fibroblast growth factor-23 signaling by klotho. J Biol Chem 2006;281: 6120-3.

5. Mitani H, Ishizaka N, Aizawa T, Ohno M, Usui S, Suzuki T, et al. In vivo klotho gene transfer ameliorates angiotensin IIinduced renal damage. Hypertension 2002; 39:838-43.

6. Miyamoto K, Ito M, Segawa H, Kuwahata M. Molecular targets of hyperphosphatemia in chronic renal failure. Nephrol Dial Transplant 2003;suppl 3:S79-S80.

7. Sugiura H, Yoshida T, Tsuchiya K, Mitobe M, Nishimura S, Shirota S, et al. Klotho reduces apoptosis in experimental ischaemic acute renal failure. Nephrol Dial Transplant 2005;20:2636-45.

8. Liu H, Fergusson MM, Castilho RM, Liu J, Cao L, Chen J, et alAugmented Wnt signaling in a mammalian model of accelerated aging. Science 2007;317:803-6.

9. Liu S, Gupta A, Quarles LD. Emerging role of fibroblast growth factor 23 in a bonekidney axis regulating systemic phosphate homeostasis and extracellular matrix mineralization. Curr Opin Nephrol. Hypertens 2007;16:329-35.

10. Saito Y, Nakamura T, Ohyama Y, Suzuki T, Iida A, Shiraki-Iida T, et al. In vivo klotho gene delivery protects against endothelial dysfunction in multiple risk factor syndrome. Biochem Biophys Res Commun 2000;276:767-72.

11. Utsugi T, Ohno T, Ohyama Y, Uchiyama T, Saito Y, Matsumura Y, et al. Decreased insulin production and increased insulin sensitivity in the klotho mutant mouse, a novel animal model for human aging. Metabolism 2000;49:1118-23.

12. Imura A, Iwano A, Tohyama 0 , Tsuji Y, Nozaki K, Hashimoto N, et al. Secreted Klotho protein in sera and CSF: implication for post-translational cleavage in release of Klotho protein from cell membrane. FEBS Lett 2004;565:143-7.

13. Imai M, Ishikawa K, Matsukawa N, Kida I, Ohta J, Ikushima M, et al. Klotho protein activates the PKC pathway in the kidney and testis and suppresses 25-hydroxyvitamin D3 1alpha-hydroxylase gene expression. Endocrine 2004;25:229-34.

14. Horster MF, Braun GS, Huber SM. Embryonic renal epithelia: induction, nephrogenesis, and cell differentiation. Physiol Rev 1999;79:1157-91.

15. Cha JH, Kim YH, Jung JY, Han KH, Madsen 
KM, Kim J. Cell Proliferation in the Loop of Henle in the Developing Rat Kidney. J Am Soc Nephrol 2001;12:1410-21.

16. Neiss WF. Histogenesis of the loop of Henle in the rat kidney. Anat Embryol 1982;164:315-30.

17. Galvez OG, Bay WH, Roberts BW, Ferris TF. The hemodynamic effects of potassium deficiency in the dog. Circ Res 1997;40: I11-6.

18. Takata K, matsuzaki T, Tajika Y, Ablimit A, Hasegawa T. Localization and trafficking of aquaporin 2 in the kidney. Histochem Cell Biol 2008;130:197-209.

19. Purkerson JM, Tsuruoka S, Suter DZ, Nakamori A, Schwartz GJ. Adaptation to metabolic acidosis and its recovery are associated with changes in anion exchanger distribution and expression in the cortical collecting duct. Kidney Int
2010;78:993-1005.

20. Bagnis C, Marshansky V, Breton S, Brown D. Remodeling the cellular profile of collecting ducts by chronic carbonic anhydrase inhibition. Am J Physiol Renal Physiol 2001;280:F437-48.

21. Wagner CA, Geibel JP. Acid-base transport in the collecting duct. J Nephrol Suppl 2002;5:S112-27.

22. Verlander JW, Madsen KM, Tisher CC. Structural and functional features of proton and bicarbonate transport in the rat collecting duct. Semin Nephrol 1991; 11:465-77.

23. Coresh J, Astor BC,Greene T, Eknoyan G, Levey AS. Prevalence of chronic kidney disease and decreased kidney function in the adult US population: Third National Health and Nutrition Examination Survey. Am J Kidney Dis 2003;41:1-12.
24. Koh N, Fujimori T, Nishiguchi S, Tamori A, Shiomi S, Nakatani T, et al. Severely reduced production of klotho in human chronic renal railure kidney. Biochem Biophys Res Commun 2001;280:1015-20.

25. Hu MC, Shi M, Zhang J, Quinones H, Griffith C, Kuro-o M, et al. Klotho deficiency causes vascular calcification in chronic kidney disease. J am Soc Nephrol 2011;22:124-36.

26. Xie B, Zhou J, Shu G, Liu DC, Zhou J, Chen J, Yuan L. Restoration of Klotho gene expression induceds apoptosis and authophagy in gastric cancer cells: tumor suppressive role of klotho in gastric cancer. Cancer Cell Int 2013;13:18.

27. Chen B, Wang X, Zhao W, Wu J. Klotho inhibits growth and promotes apoptosis in human lung cancer cell line A549. J Exp Clin Cancer Res 2010;29:99. 